\title{
Assessing Cannabis Demand: A Comprehensive Review of the Marijuana Purchase Task
}

\author{
Elizabeth R. Aston ${ }^{1,2}(\mathbb{D}) \cdot$ Lidia Z. Meshesha $^{1}$
}

Published online: 8 January 2020

(C) The American Society for Experimental NeuroTherapeutics, Inc. 2020

\begin{abstract}
The marijuana purchase task (MPT) is a behavioral economic measure of individualized cannabis value (i.e., demand). The MPT follows purchase tasks for other substances (e.g., alcohol, tobacco), though presents with unique caveats due to its mixed illicit status, non-uniform units of purchase and use, and substantial within substance variability in strain, potency, and quality. As the regulatory climate surrounding purchase and use of cannabis continues to evolve in the USA and globally, rigorous assessment of cannabis use and value are of the utmost importance. This study represents the first comprehensive review of investigations utilizing the MPT. Searches through PubMed and Web of Science databases by two independent coders identified 15 empirical articles referencing the use of an MPT and were published through the year 2019. Articles were coded for demographic and procedural characteristics, structural characteristics of the MPT itself, data analytic characteristics, and relationships with cannabis-related outcomes. Rigorous assessment of demand for cannabis is essential with respect to the broad public health issues surrounding cannabis legalization. We have synthesized the research presented herein and comment on vital considerations for subsequent MPT work, including recommendations for a unified approach to using the MPT in subsequent research.
\end{abstract}

Key Words Marijuana purchase task $\cdot$ behavioral economics $\cdot$ demand $\cdot$ cannabis

Behavioral economics is the intersection of psychology and economics and is applicable to the study of progression and maintenance of problematic substance use. Various facets of behavioral economics may be tapped to better understand given components of substance use and substance use disorders, namely discounting of delayed rewards [1], degree of utilization of alternative reinforcers [2], and assessment of substance demand [3].

Behavioral economic substance demand is the interplay between substance price and the value placed on said substance (i.e., reinforcer) by an individual. The relative value that a substance holds for a particular user is a key indicator of risk for substance use and escalation into substance use disorder [4]. Substance value can be assessed across a range

Elizabeth R. Aston

Elizabeth_Aston@Brown.edu

1 Center for Alcohol and Addiction Studies, Brown University School of Public Health, Providence, RI 02912, USA

2 Department of Behavioral and Social Sciences, Brown University School of Public Heath, Providence, RI 02912, USA of prices in the laboratory via administration of a substance purchase task [5], wherein a participant indicates the hypothetical level of drug they desire to purchase and use at escalating levels of price under a prespecified experimental manipulation. Purchase of a substance at varying levels of price allows for generation of behavioral economic demand curves, on which five key indices of demand may be ascertained. Demand indices include intensity (i.e., unrestrained purchase at zero cost), $O_{\max }$ (i.e., peak expenditure for a substance), $P_{\max }$ (i.e., price corresponding to peak expenditure), breakpoint (i.e., the cost at which substance demand is suppressed to zero), and elasticity (i.e., the degree to which consumption decreases with increasing price). Due to their hypothetical nature, purchase tasks allow for assessment of substance value among populations in which drug administration may be unethical (e.g., individuals with substance use disorders) or impossible (e.g., individuals under the legal age for substance use).

Demand has been well investigated for certain substances, including alcohol. Murphy and MacKillop [6] conducted seminal research using a novel alcohol purchase task (APT) designed to assess alcohol demand across increasing alcohol cost. APTs have been utilized broadly to assess alcohol value 
among various populations under certain conditions [7, 8]. Demand for alcohol has displayed concurrent validity via indices significantly positively correlated with level of use (i.e., drinks per week) and alcohol-related problems [6,9], and predictive validity via indices displaying capability of significantly predicting treatment response [10]. Moreover, purchase tasks assessing in-the-moment (i.e., state) demand can detect cue-induced increases in the rewarding value placed on alcohol [11], and hypothetical demand has demonstrated high positive correlation with actual alcohol consumption within a laboratory setting [12]. The APT is a validated and useful measure that has demonstrated utility with a variety of populations and contexts [7], including good construct validity [13]. In recent years, investigators have adapted the measure to evaluate the behavioral economic demand of other substances.

A relatively new area of research has emerged characterizing demand for cannabis, a key subject of investigation in the wake of political and normative shifts surrounding cannabis use and sales. While several studies have been conducted assessing demand for cannabis in recent years, there has yet to be a published review of the research specific to cannabis demand. Assessment of cannabis demand is critical to informing important areas of research and policy, including novel cannabis use disorder treatments, recreational cannabis taxation, and response to exposure to advertising and other environmental cues. This article intends to review the literature to date on cannabis demand. As cannabis demand may be assessed across a variety of investigation types, we have grouped studies by common thematic study elements. We begin by reviewing seminal marijuana purchase task (MPT) studies and move on to review research on its latent factor structure, its use in studies assessing state cannabis demand, its integration into a Reinforcer Pathology framework of addiction, the importance of quality and legal climate, the influence of other substances, and the relationship between cannabis demand and hazardous behaviors such as driving after use. After synthesizing this work, we touch on psychometrics, purchase task formats (e.g., state versus trait), and the promise of future research assessing demand among cannabis users varying in frequency, preferred strain, and emerging administration modes.

\section{Method}

The authors conducted a systematic literature review of publications reporting on the MPT. Using PubMed and Web of Science, the following key terms were searched: marijuana purchase task, marijuana demand, and behavioral economics AND marijuana. Manuscripts published through the year 2019 were included in the search. Inclusion criteria were a) use of a hypothetical MPT measure, b) empirical manuscript (i.e., not a review or opinion paper) with human participants, c) publication in a peer-reviewed journal, and d) written in English. If studies included more than one purchase task, in addition to the MPT, they were included in the review.

Authors conducted independent literature searches and reviewed abstracts to ensure the articles meet inclusion criteria. Subsequently, a joint meeting took place to compare findings, discuss any discrepancies between reviewers, and establish consensus on the articles to include in the review. The authors then met to finalize thematic categories into which the manuscripts were grouped (e.g., cannabis legal climate, cannabis demand, and other substances). Participant demographics and study procedures (e.g., sample size, participant age, and gender), characteristics of the MPT across studies (e.g., prices, number of prices, MPT instructions, demand equations), and cannabis demand results were coded across all studies, and findings are presented in Tables 1, 2, and 3, respectively.

\section{Results}

\section{Search Criteria}

The initial search yielded 344 articles, and 328 were excluded as abstract review indicated that the studies did not include the MPT $(n=327)$ or did not present empirical data $(n=1)$. Upon a detailed review of the remaining manuscripts, one additional article was excluded as it did not include the hypothetical MPT. The remaining manuscripts $(N=15)$ were included in the current review; there were no discrepancies between the authors regarding which manuscripts were appropriate for inclusion. Articles included in this review were published across seven different addiction and psychology journals, publication years ranged from 2014 to 2019, the majority of the manuscripts $(n=14)$ were cross-sectional examinations, and one study contained a longitudinal assessment.

\section{Demographic Information}

We report demographic information including sample description, age, sex, incentives, initial sample size, and final sample retained for analysis in Table 1. Of the reviewed studies, four administered the MPT using a paper and pencil measure and the remaining studies ( $n=11$ ) administered the MPT via computer. Further, five studies utilized Amazon's Mechanical Turk (MTurk), a crowd-sourcing online platform in which individuals complete various tasks or surveys in exchange for compensation.

Key elements of the MPT reported in the reviewed papers are presented in Table 2. MPT components include key characteristics of the vignette, whether a trait or state measure was administered, the number of prices, the specific prices, the 


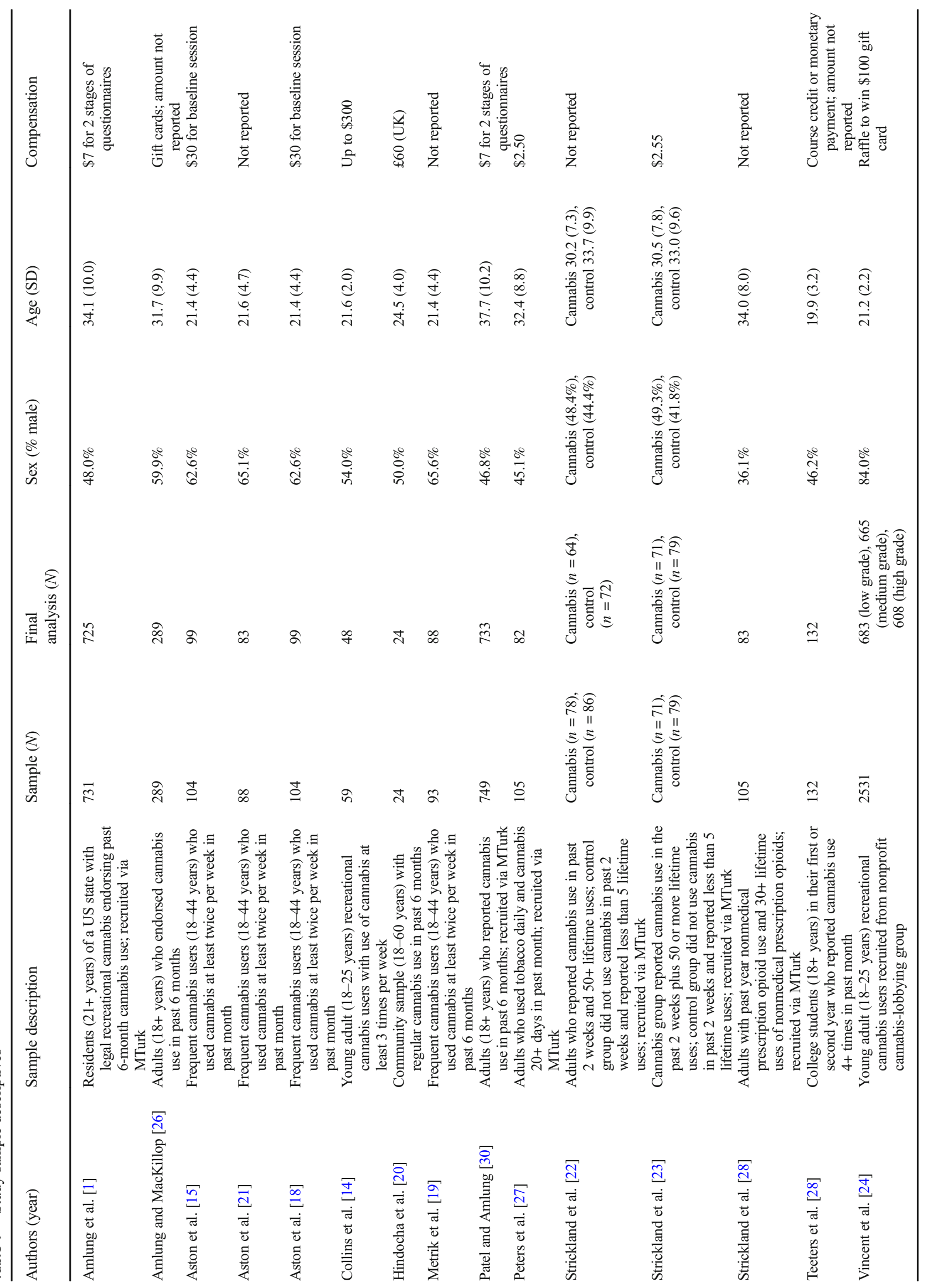




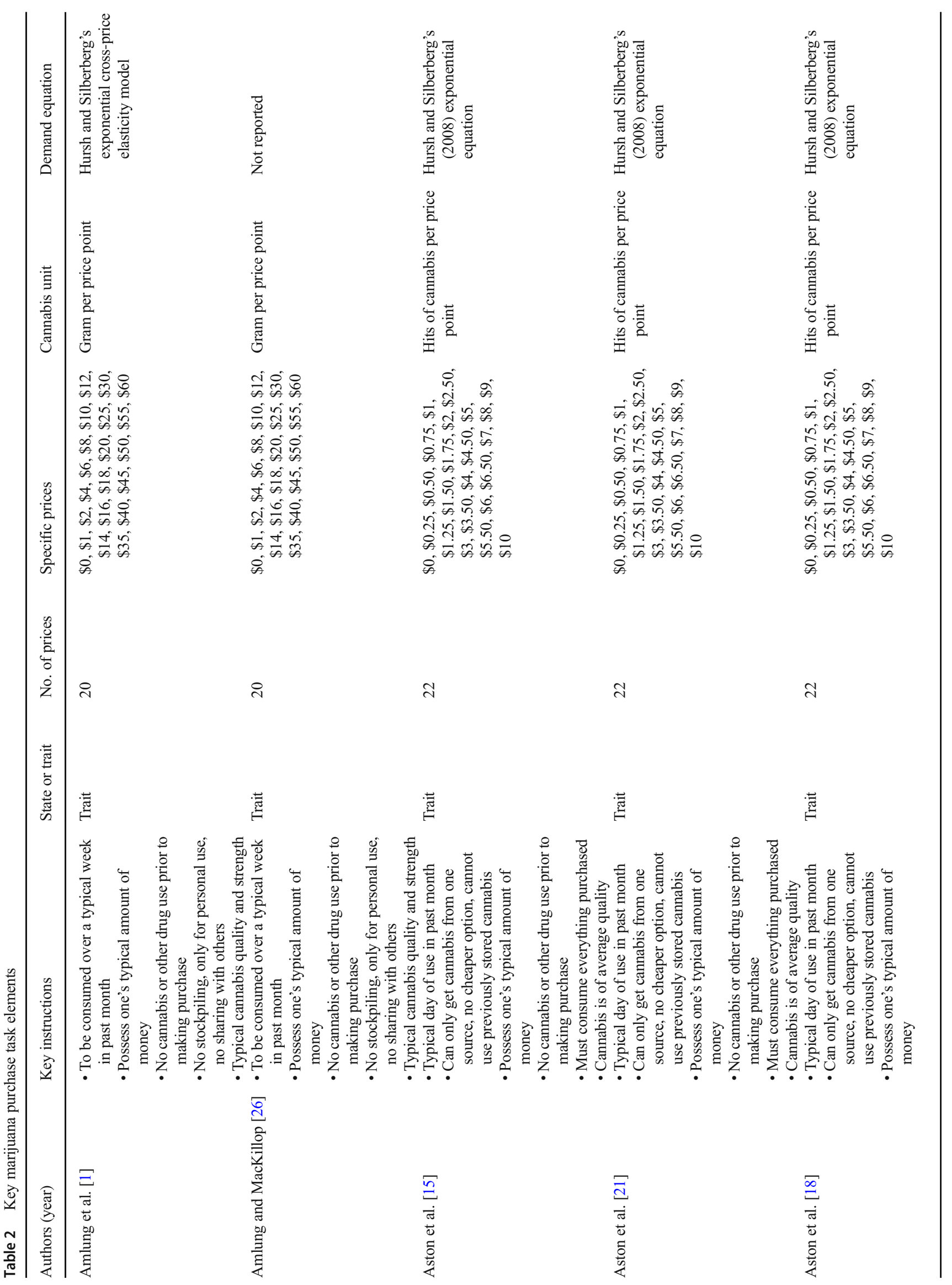




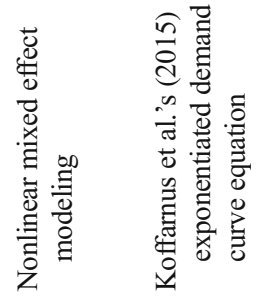

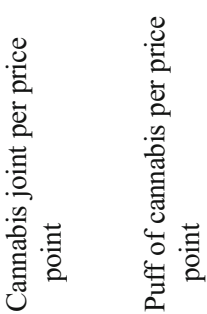

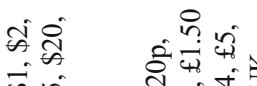

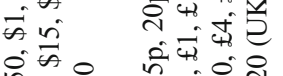

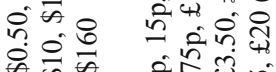

तेंक हैं क्षे

की की मीं किष्ठ

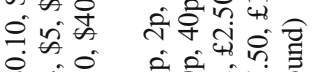

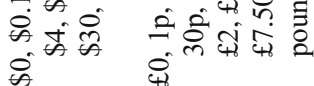

$-2$

.

¿

营
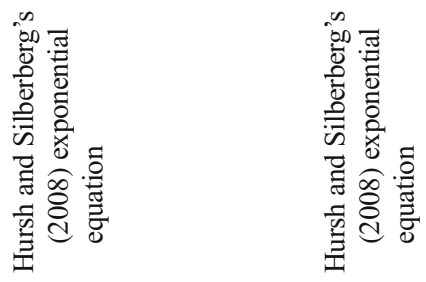

苍.

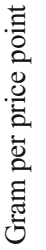

ป

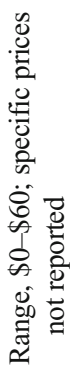

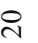

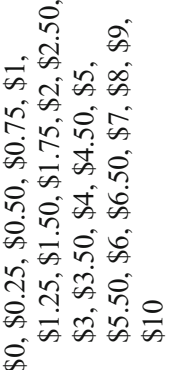

跑离

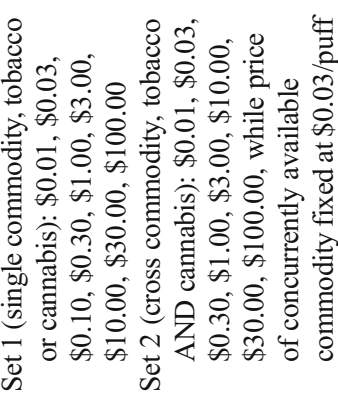

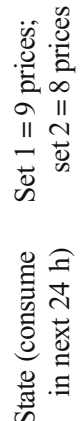

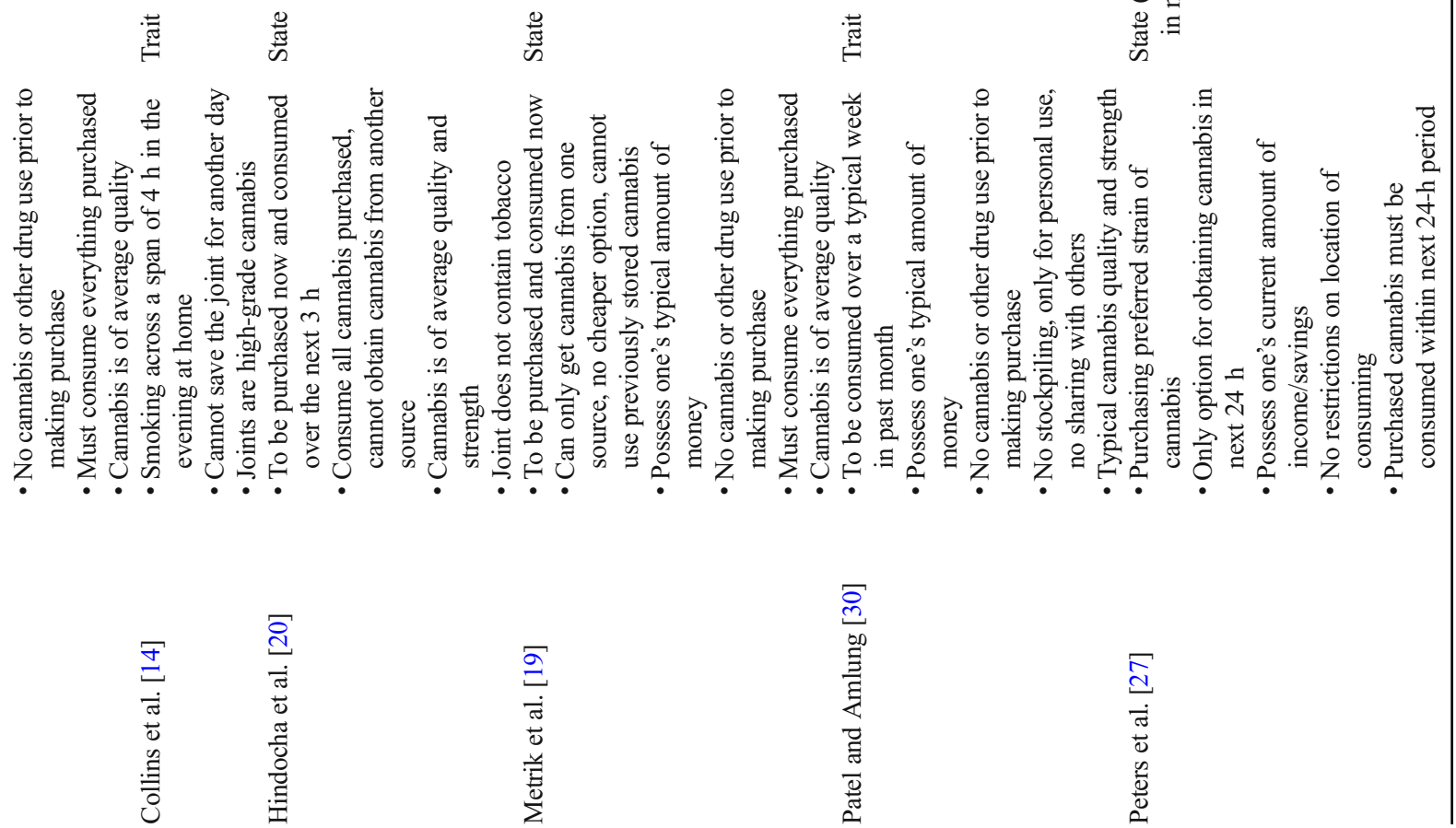




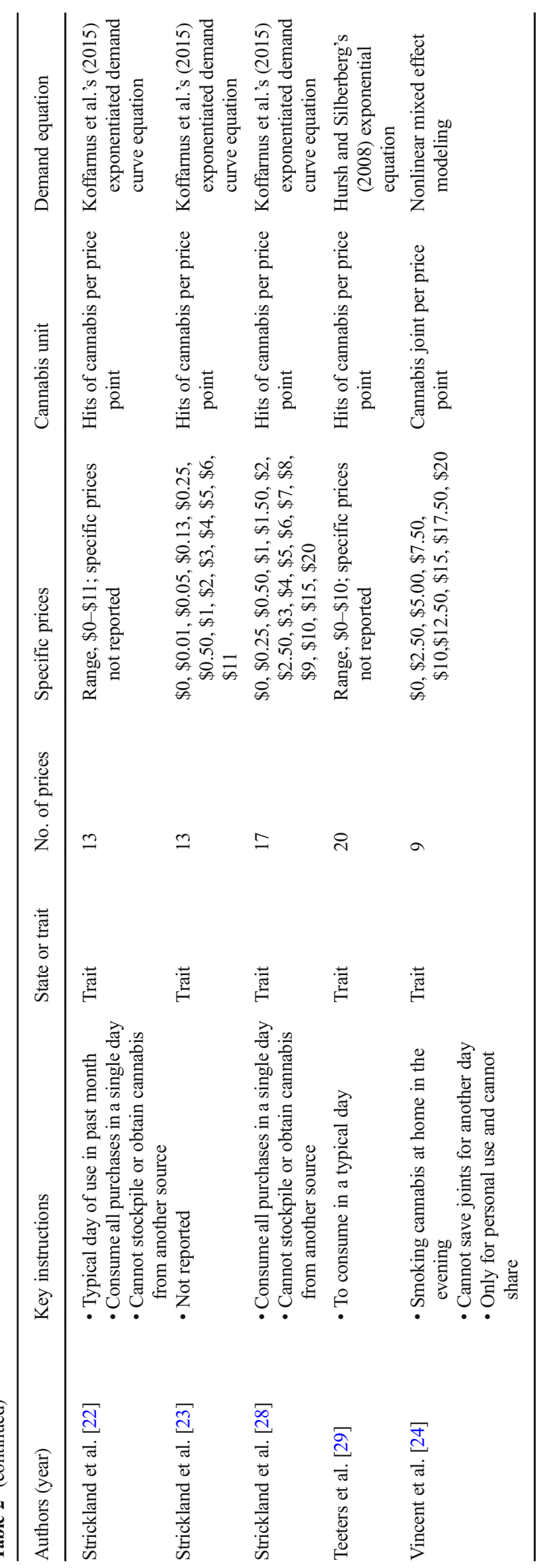


units of cannabis, and the equation used to calculate demand. Results of the studies reviewed (i.e., cannabis-related measures, significant demand indices, and findings) are presented in Table 3.

\section{Seminal Studies}

The first published study using a purchase task to assess demand for cannabis was conducted by Collins et al. [14] and designated high-grade cannabis joints as the unit of purchase. Consistent with findings pertaining to purchase task performance for other substances, cannabis demand was inelastic (i.e., insensitive to price increases) at lower prices but became elastic (i.e., sensitive to price increases) at higher prices, suggesting that raising the price of cannabis could impact its purchase and use. Indices of cannabis demand were related to frequency of cannabis use assessed by both retrospective self-report and prospective ecological momentary assessment. This work displayed initial validity of a simulated MPT to examine cannabis' reinforcing value [14]. Following the initial work on cannabis demand, a MPT from our laboratory utilized cannabis "hits" as the unit of purchase. Designation of hits as the purchase unit was expected to increase resolution by employing a smaller unit of analysis that spanned most administration modes. Indices of demand for cannabis hits (i.e., intensity and $O_{\max }$ ) were related to cannabis dependence symptoms, self-reported cannabis craving, as well as level of use, illustrating construct validity of the MPT [15].

Subsequent work from our laboratory investigated whether the MPT displayed a latent factor structure that has been found in purchase task data for other substances, including alcohol [16] and tobacco [17]. Five indices of demand can often be reduced to two latent variables: persistence (i.e., maintenance of consumption despite increases in cost) and amplitude (i.e., maximum level of ad libitum consumption). We found clear evidence of a latent factor structure on the MPT, with intensity mapping onto amplitude, and $O_{\max }, P_{\max }$, breakpoint, and elasticity mapping onto persistence. Moreover, the latent variables displayed concurrent validity and were differentially associated with key aspects of cannabis use such that persistence was related to fewer past attempts to cease cannabis use and amplitude was related to frequent use, dependence symptoms, and craving severity [18]. Taken together, these initial validation studies show that indices of cannabis demand are significantly related to important risk variables that denote frequent and potentially problematic cannabis use.

\section{Measuring State Demand}

Two manuscripts in this review assessed demand for cannabis as a function of manipulated state in the laboratory. Metrik et al. [19] compared cannabis demand following exposure to both neutral and cannabis cues. Relative to neutral cues, cannabis cues significantly increased subjective cannabis craving and demand indices of intensity (i.e., drug consumed at \$0) and $O_{\max }$ (i.e., peak drug expenditure). Relatedly, elasticity significantly decreased following cannabis cues, reflecting sustained purchase despite increases in price [19]. Metrik et al. [19] were the first to display state changes in demand for cannabis as a function of cue exposure, which may ultimately translate into the impact of environmental cues on demand.

Hindocha et al. [20] examined how cannabis and tobacco, each alone and combined together in joints, impacted demand for cannabis "puffs" and tobacco cigarettes. Relative to administration of placebo cannabis, active cannabis decreased demand for cannabis (i.e., breakpoint and elasticity at the trend level) and tobacco cigarettes (i.e., breakpoint, $P_{\max }$, $\left.O_{\max }\right)$. In contrast, tobacco, both alone and combined with cannabis, did not impact demand or craving. As expected, acute cannabis administration reduced demand for cannabis and also reduced demand for tobacco cigarettes. Tobacco administration did not impact demand for tobacco cigarettes or cannabis, thus among nondependent cannabis and tobacco cousers, tobacco did not influence the rewarding effects of cannabis. This study represents an initial foray into state investigations of demand for substances that are frequently co-used, which may be instrumental to our understanding of cross-drug craving, tolerance, and potential substitutive effects.

\section{Testing the Reinforcer Pathology Model}

Three studies investigated demand for cannabis and discounting of delayed rewards in an effort to confirm presence of the Reinforcer Pathology model of addiction among heavy cannabis users. The Reinforcer Pathology model is typified by the joint effects of two processes that characterize escalation into dependence: continuously high value placed on a given reinforcer (i.e., demand) and/or an extreme predilection toward the immediate attainment and consumption of a given reinforcer despite immediate and long-term adverse consequences (i.e., delay discounting) [4]. Aston et al. [21] first attempted to apply this model to a sample of frequent cannabis users. They found that frequent cannabis users display both required components of the Reinforcer Pathology model, namely elevated demand for cannabis and steep discounting of delayed rewards. However, demand and delay discounting were independent rather than synergistic risk factors.

Strickland et al. [22] went on to replicate this research among a sample of individuals reporting recent cannabis use and controls utilizing Amazon's Mechanical Turk platform. Participants in the study completed a MPT measure and measures of monetary and cannabis delay discounting. Strickland et al. [22] found that cannabis users and controls 
were not significantly different on monetary delay discounting. Among cannabis users, marijuana delay discounting uniquely predicted severity of use, while cannabis demand uniquely predicted use frequency and quantity, replicating findings from Aston et al. [21]. Strickland et al. [23] followed their initial research with a subsequent study assessing the role that drug-related cues play in the development and maintenance of substance use disorders. Current cannabis users and controls were recruited using Amazon's Mechanical Turk. Participants completed a cued concurrent choice task wherein cannabis trials presented two cues (one cannabis and one neutral) beside each other followed by concurrent monetary amounts. Compared to control participants, those in the cannabis group displayed a significant bias for cannabis-cued choices. Moreover, cannabis-cued choice was significantly related to frequent cannabis use, higher cannabis intensity, and lower cannabis elasticity, reflecting higher demand.

\section{Cannabis Quality and the Legal Climate}

Cannabis demand is highly influenced by important external variables including specification of quality, environmental factors, and legal climate. Vincent et al. [24] manipulated cannabis quality in the context of a series of MPTs to investigate whether perceived quality impacts cannabis demand. Three versions of a MPT (low-grade, mid-grade, and high-quality cannabis) were administered via an online platform to members of a nonprofit cannabis-lobbying group. Results indicated that demand was sensitive to perceived cannabis quality, with users of this sample willing to pay more for higher-grade cannabis. Moreover, Vincent et al. [24] examined the construct validity of the MPT for all cannabis grades by assessing the association between demand indices and cannabis use and found good construct validity of the MPT, as well as validity for each cannabis grade.

Recent work by Amlung and colleagues has examined the influence of hypothetical changes in cannabis-related legislation on cannabis purchase using purchase tasks as well. These studies examined whether demand for cannabis differed as a function of purchase from legal versus illegal sources. The initial study conducted by Amlung et al. [25] revealed that compared with illegal cannabis, cannabis users in a US sample perceived legal cannabis as a superior commodity. Ecological validity of this research was bolstered by specifically assessing participants from states wherein recreational cannabis was legal via an online crowdsourcing approach [25]. Amlung and MacKillop [26] continued this work with a Canadian sample and reported similar findings, specifically that introduction of legal cannabis into the illegal market may disrupt and reduce purchase of cannabis from illegal sources. These studies employing instructional set manipulation demonstrate the extensive utility of purchase tasks in informing policy decisions in the wake of changes in the legal climate surrounding cannabis.

\section{Cannabis Demand and Other Substances}

Three of the reviewed manuscripts describe cannabis demand in relation to other substances. Peters et al. [27] used hypothetical marijuana and tobacco purchase tasks to evaluate whether cannabis and tobacco served as substitutes or compliments to one another or if demand for each was independent of the other among an adult sample who co-used cannabis and tobacco. Their results suggest when the two purchase tasks were presented concurrently, cannabis and tobacco were independent of each other, whereas when the two purchase tasks were presented independently, cannabis demand was greater compared to tobacco, suggesting cannabis may be more reinforcing. In a drug administration study with tobacco and cannabis co-users, Hindocha et al. [20] examined effects of acute effects of cannabis and tobacco administration on demand. Their findings suggest that cannabis administration compared to placebo was associated with nonsignificant trend-level reduction of both cannabis and tobacco breakpoint (i.e., the point at which consumption is suppressed to zero). In other words, after cannabis consumption, individuals were more sensitive to price increases and ceased to purchase cigarettes and cannabis at escalating prices. Furthermore, in their study evaluating a novel opioid purchase task, which displayed incremental validity and good test-retest reliability, Strickland et al. [28] found that cannabis demand (i.e., intensity) was positively associated with frequency and amount of cannabis use and CUD, but it was not associated with opioid use disorder or alcohol use disorder. Elasticity was associated with amount of cannabis used but no other cannabis use variables.

\section{Cannabis Demand and Driving After Use}

Teeters et al. [29] and Patel and Amlung [30] evaluated the association between cannabis demand and driving after using cannabis. Among a sample of cannabis using college students, Teeters et al. [29] reported cannabis demand (i.e., intensity) was associated with driving after cannabis use and that higher cannabis demand was associated with greater frequency of this behavior. Similarly, using a sample of young adult cannabis users, Patel and Amlung [30] compared cannabis demand between individuals who report driving after cannabis use versus those who do not drive after cannabis use. Results suggest that driving after cannabis use is associated with greater cannabis demand across all demand indices. These studies illuminate the association between cannabis demand and risky behaviors such as driving while impaired. 
Table 3 Cannabis-related study measures and demand outcomes

\begin{tabular}{|c|c|c|c|}
\hline Authors (year) & Cannabis-related measures & $\begin{array}{l}\text { Significant demand } \\
\text { predictors }\end{array}$ & Results \\
\hline Amlung et al. [1] & $\begin{array}{l}\text { Cannabis Use Disorders Identification Test } \\
\text { (CUDIT) Revised }\end{array}$ & $\begin{array}{l}\text { - Intensity } \\
\text { - Elasticity } \\
\text { - } P_{\max }\end{array}$ & $\begin{array}{l}\text { - Intensity was greater for legal compared to illegal } \\
\text { cannabis } \\
\text { - Elasticity was higher for illegal cannabis } \\
\text { - The presence of legal cannabis impacted elasticity } \\
\text { and } P_{\max } \text { of illegal cannabis purchase }\end{array}$ \\
\hline $\begin{array}{l}\text { Amlung and } \\
\text { MacKillop [26] }\end{array}$ & $\begin{array}{l}\text { Pattern of cannabis use (lifetime use chronology, } \\
\text { routes of administration, potency, quantity, etc.); } \\
\text { past 6-month CUD assessed with CUDIT-R }\end{array}$ & $\begin{array}{l}\text { - Elasticity } \\
\text { - } P_{\max }\end{array}$ & $\begin{array}{l}\text { - Elasticity and } P_{\max } \text { of illegal cannabis purchase } \\
\text { were impacted more with the availability of legal } \\
\text { cannabis compared to the reverse scenario }\end{array}$ \\
\hline Aston et al. [15] & $\begin{array}{l}\text { Structured Clinical Interview (SCID) for DSM-IV } \\
\text { cannabis dependence symptoms; 60-day time- } \\
\text { line followback (TLFB) of cannabis use; } \\
\text { Marijuana Craving Questionnaire; Marijuana } \\
\text { History and Smoking Questionnaire }\end{array}$ & $\begin{array}{l}\text { - Intensity } \\
\text { - } O_{\max } \\
\text { - Elasticity }\end{array}$ & $\begin{array}{l}\text { - Intensity was associated with craving, age of } \\
\text { initiation of regular cannabis use, percent } \\
\text { cannabis use days, and DSM-IV dependence } \\
\text { symptoms } \\
\text { - } O_{\max } \text { was associated with percent cannabis use } \\
\text { days and craving } \\
\text { - Elasticity was associated with craving and } \\
\text { DSM-IV dependence symptoms }\end{array}$ \\
\hline Aston et al. [21] & $\begin{array}{l}\text { 60-day TLFB of cannabis use; Marijuana Craving } \\
\text { Questionnaire; Marijuana History and Smoking } \\
\text { Questionnaire; Delay Discounting Task; past } \\
\text { 60-day tobacco use }\end{array}$ & $\begin{array}{l}\text { - Area under the } \\
\text { curve (AUC) }\end{array}$ & $\begin{array}{l}\text { - AUC was correlated with cannabis use frequency, } \\
\text { tobacco use, and all } 5 \text { demand indices; AUC was } \\
\text { a significant predictor of percent cannabis use } \\
\text { days }\end{array}$ \\
\hline Aston et al. [18] & $\begin{array}{l}\text { SCID for DSM-IV cannabis dependence symp- } \\
\text { toms; 60-day TLFB of cannabis use; Marijuana } \\
\text { Craving Questionnaire; Marijuana History and } \\
\text { Smoking Questionnaire; Marijuana Effect } \\
\text { Expectancy Questionnaire }\end{array}$ & $\begin{array}{l}\text { - Amplitude } \\
\text { (consisting of } \\
\text { intensity) } \\
\text { - Persistence } \\
\quad \text { (consisting of } \\
O_{\max }, P_{\max } \\
\text { breakpoint, } \\
\text { elasticity) }\end{array}$ & $\begin{array}{l}\text { - Amplitude was associated with percent cannabis } \\
\text { use days, craving severity, cannabis dependence } \\
\text { symptoms, and cannabis use expectancies of } \\
\text { social/sexual facilitation and tension reduction } \\
\text { - Persistence was negatively associated with } \\
\text { negative cannabis use expectancies and } \\
\text { cognitive-behavioral impairments }\end{array}$ \\
\hline
\end{tabular}

\begin{tabular}{|c|c|c|}
\hline Collins et al. [14] & $\begin{array}{l}\text { Marijuana Use Questionnaire; Marijuana } \\
\text { Acquisition and Use Patterns Questionnaire; } \\
\text { Marijuana Problems Index; ecological } \\
\text { momentary assessment reports of cannabis use; } \\
\text { a computerized "shopping" task involving the } \\
\text { purchase of both cannabis and exercise time }\end{array}$ & $\begin{array}{l}\text { - Intensity } \\
\text { - } O_{\max } \\
\text { - } P_{\max } \\
\text { - Elasticity }\end{array}$ \\
\hline Hindocha et al. [20] & $\begin{array}{l}\text { Pleasantness rating of images of } \\
\text { cannabis/tobacco/food/neutral stimuli; visual } \\
\text { analog scales of cannabis, tobacco, and food }\end{array}$ & - None \\
\hline Metrik et al. [19] & $\begin{array}{l}\text { 60-day TLFB of cannabis use; Marijuana Craving } \\
\text { Questionnaire; Marijuana History and Smoking } \\
\text { Questionnaire; Marijuana Stroop Task }\end{array}$ & $\begin{array}{l}\text { - Intensity } \\
\text { - } O_{\max } \\
\text { - Elasticity }\end{array}$ \\
\hline
\end{tabular}

- Intensity was positively associated with real-time report of cannabis use amount

- $O_{\max }$ was positively associated with retrospective and real-time report of cannabis use amount

- $P_{\max }$ and elasticity were negatively associated with real-time report of cannabis use amount

- Breakpoint and elasticity were related to cannabis administration compared to placebo (trend level)

- Intensity was correlated with cue-elicited craving; intensity increased after cannabis relative to neutral cue exposure; intensity predicted attentional bias for cannabis words on a Stroop task

- $O_{\max }$ was correlated with cue-elicited craving; $O_{\max }$ increased after cannabis relative to neutral cue exposure

- Elasticity was reduced after exposure to cannabis relative to neutral cues

Patel and Amlung Measure of driving after cannabis use; CUDIT-R - Intensity [30] assessed for past 6 months of cannabis use and $\cdot$ Breakpoint related problems

- $O_{\max }$

- $P_{\max }$

- Elasticity

- Intensity, breakpoint, $O_{\max }$, and $P_{\max }$ were greater in participants reporting driving after cannabis use compared to those who do not

- Intensity predicted driving after cannabis use status

- Elasticity was greater among participants who did not report driving after cannabis use compared to those who do

Peters et al. [27]
Frequency of past month cannabis use; single-commodity purchase tasks for cannabis and tobacco; cross-commodity purchase task with both cannabis and tobacco puffs available
- Elasticity

- Elasticity for cannabis was lower among individuals with greater nicotine dependence

- Elasticity was lower for women than for men; cannabis elasticity was higher for women when cigarettes were available compared to cannabis only 
Table 3 (continued)

\begin{tabular}{|c|c|c|c|}
\hline Authors (year) & Cannabis-related measures & $\begin{array}{l}\text { Significant demand } \\
\text { predictors }\end{array}$ & Results \\
\hline Strickland et al. [22] & $\begin{array}{l}\text { Cannabis delay discounting task; } \\
\text { Mini-International Neuropsychiatric Interview } \\
\text { (MINI) for DSM-IV symptoms of cannabis de- } \\
\text { pendence; Cannabis History and Smoking } \\
\text { Questionnaire }\end{array}$ & $\begin{array}{l}\text { - Intensity } \\
\text { - Elasticity } \\
\text { - AUC }\end{array}$ & $\begin{array}{l}\text { - Intensity and elasticity were associated with } \\
\text { cannabis use frequency, quantity, and cannabis } \\
\text { dependence symptoms } \\
\text { - AUC predicted grams of cannabis per week, } \\
\text { percent of past month use days, and cannabis } \\
\text { dependence symptoms }\end{array}$ \\
\hline Strickland et al. [23] & $\begin{array}{l}\text { Cued concurrent choice task (images of cannabis } \\
\text { and non-cannabis items were presented follow- } \\
\text { ed by side-by-side monetary choices); MINI for } \\
\text { DSM-IV symptoms of cannabis dependence; } \\
\text { delay discounting for money and cannabis }\end{array}$ & $\begin{array}{l}\text { - Intensity } \\
\text { - Elasticity }\end{array}$ & $\begin{array}{l}\text { - Higher intensity and lower elasticity were } \\
\text { associated with greater cannabis-cued choice bias }\end{array}$ \\
\hline Strickland et al. [28] & $\begin{array}{l}\text { Delay discounting for money, prescription opioids, } \\
\text { and cannabis; DSM-5 diagnostic assessment for } \\
\text { CUD }\end{array}$ & $\begin{array}{l}\text { - Intensity } \\
\text { - Elasticity }\end{array}$ & $\begin{array}{l}\text { - Intensity was associated with frequency and } \\
\text { quantity of cannabis use, plans for seeking } \\
\text { treatment/reducing in the next year, and CUD } \\
\text { - Elasticity was associated with quantity of cannabis } \\
\text { use }\end{array}$ \\
\hline Teeters et al. [29] & $\begin{array}{l}\text { 28-day TLFB of cannabis use; Modified Rutgers } \\
\text { Marijuana Problems Index; driving after } \\
\text { cannabis use }\end{array}$ & - Intensity & $\begin{array}{l}\text { - Intensity was associated with past-month cannabis } \\
\text { use and driving after cannabis use }\end{array}$ \\
\hline Vincent et al. [24] & $\begin{array}{l}\text { Questions regarding typical marijuana use in the } \\
\text { past } 90 \text { days, preferred smoking methods, } \\
\text { frequency of use, and real-world purchasing } \\
\text { behavior; } 3 \text { MPTs were completed: one for } \\
\text { low-, medium-, and high-grade cannabis }\end{array}$ & $\begin{array}{l}\text { - Intensity } \\
\text { - Breakpoint } \\
\text { - } O_{\max } \\
\text { - } P_{\max } \\
\text { - Elasticity }\end{array}$ & $\begin{array}{l}\text { - Intensity increased as quality of cannabis } \\
\text { increased; intensity was correlated with weekly } \\
\text { cannabis use for all grades of cannabis; for low- } \\
\text { and medium-grade cannabis, intensity was asso- } \\
\text { ciated with higher cannabis use } \\
\text { - } P_{\max } \text { increased as quality of cannabis improved } \\
\text { - } O_{\max } \text { was correlated with weekly cannabis use for } \\
\text { all grades of cannabis; for low- and } \\
\text { medium-grade cannabis, } O_{\max } \text { was associated } \\
\text { with higher cannabis use } \\
\text { - Breakpoint increased as quality of cannabis } \\
\text { improved; for medium-grade cannabis, } \\
\text { breakpoint was negatively related to cannabis use } \\
\text { - Elasticity was associated with higher use for } \\
\text { high-grade cannabis }\end{array}$ \\
\hline
\end{tabular}

CUD cannabis use disorder; CUDIT-R Cannabis Use Disorders Identification Test, Revised; TLFB Timeline Followback; SCID Structured Clinical Interview for DSM-IV Non-Patient Edition

\section{Discussion}

The reviewed studies in the current investigation utilized adult samples, with three of the studies narrowing their investigations to a young adult population (ages 18-25 years) and another four studies limiting the age range to 18-44 years. The studies included non-treatment-seeking samples who endorse regular cannabis use with the underlying assumption that regular users would have prior experience in the actual purchase of cannabis to facilitate hypothetical purchase required by the MPT. Further, this review indicated that there were variations in the MPT structure and content, including the instructions provided to participants, the price range, and units of cannabis measurement. The findings presented in this review suggest that MPT versions are being utilized more frequently in laboratory and web-based investigations and are effective in the assessment of cannabis' relative value.

The instructional set presented prior to completion of any purchase task is arguably the most important component of demand data collection. The instructional vignette is read prior to completing decisions regarding purchase of the commodity and differs greatly across studies despite purchase of the same substance, namely cannabis. Alterations to the vignette may pertain to cannabis itself (e.g., strength, strain, THC/CBD ratio), the time designated for cannabis use in the task (e.g., right now, in a typical day, over 1 week), the unit of cannabis purchase (e.g., joints, hits, puffs, grams), and/or the price points. Such differences in the vignette are highly likely to impact demand; thus, it is critical to consider each instructional point and its intention (i.e., to model real-world purchasing behavior 
to the greatest extent possible). Several of the studies presented in the current review did not include presentation of the vignette, thus precluding us from analyzing differences across demand indices that may have occurred due to varying instructional sets. Subsequent research on cannabis demand should present the vignette utilized during data collection as transparency in the instructional set is critical to assessing changes in decision-making regarding cannabis purchase.

The alcohol purchase task literature has utilized altered vignettes to manipulate the context under which alcohol is purchased. For example, studies have found that changes in next-day academic constraint [31-33], same-day driving requirements ([34]), and a "happy hour" scenario [35] are all associated with elevated risk for individuals who continue to exhibit high demand despite such environmental constraints. Future research that uses similar strategies to manipulate the MPT vignette could aid in identifying the types of risks that may be uniquely associated with cannabis use.

One third $(n=5)$ of the studies presented herein employed an online crown sourcing platform (i.e., MTurk) for participant recruitment. While MTurk can be a useful platform for recruiting heterogeneous and representative populations, there are some limitations that occur with administering the MPT remotely as opposed to utilizing laboratory-based administration. In-person administrations can enable the researcher to explain the purpose of the purchase task, highlight the important components of the instructions, and permit participants to ask questions or make clarifications about points of confusion. Without this level of support, participants' performance may be negatively impacted [36].

Investigations utilizing the MPT have demonstrated its legal and public health implications. The work of $[1,25])$ provides an initial exploration into viable pricing of cannabis within an emerging market for legal cannabis as laws continue trending toward a more permissive climate. This work also suggests that an important consideration for cannabis users involves purchasing cannabis that is regulated for quality and safety and is absent of risk for the legal consequences associated with purchasing an illegal product. As a result, participants endorsed greater preference for legal cannabis up to a certain price point. These investigations are the first to demonstrate a specific dollar amount at which legal cannabis stops being preferred to illegal cannabis, which can be informative for policy-makers as they determine market prices.

These studies also investigated the association between cannabis demand and driving under the influence of cannabis, a notable public health concern [37]. The findings of both Teeters et al. [29] and Patel and Amlung [30] suggest that increased demand for cannabis is associated with greater frequency of driving while under the influence of cannabis. Consequently, elevated cannabis demand may be a useful marker of the level of risk in which an individual may engage with respect to cannabis-impaired driving. The MPT may be especially useful in identifying higs-risk individuals, given the current climate leading to increasing cannabis use and few resources to prevent driving under the influence of cannabis.

Of increasing relevance in assessing demand for cannabis includes differences in demand between individuals who use cannabis for medical versus recreational purposes. Relative cannabis value between these two sets of individuals may be distinct due to central differences in reasons for use. Individuals who use cannabis for medical purposes may be more likely to display constant demand (i.e., unchanging preferences across price). As they use cannabis to treat disease symptoms, they may be willing to pay extremely high prices for their medication. Alternatively, many medical users grow cannabis themselves, in which case they may be unwilling to pay even low prices for a commodity they have in abundance. Further complicating this issue is the fact that many individuals who use cannabis do so for both recreational and medical purposes, and it is unclear what effect this may have on relative value. This matter certainly warrants additional investigation in future studies, and at the very least, participants should be queried regarding their reasons for using and any obtainment of medical cannabis registration cards.

One increasingly valuable avenue of research on cannabis demand concerns assessment of relative value among individuals who use cannabis with other substances such as tobacco or alcohol. Individuals who co-use with other substances often display high cross-commodity demand for the opposing substance. For example, use of tobacco cigarettes may elicit increases in demand for cannabis in the moment, and vice versa. Questions surrounding cannabis's propensity to complement or substitute for other substances will continue to arise, particularly as the regulatory environment surrounding cannabis evolves. Co-use with other substances may impact the effectiveness of evidence-based cessation programs, increase the rate at which CUD occurs, or actually reduce the use of other substances (e.g., opiates). In this regard, assessment of demand for commonly co-used substances is an important area for subsequent investigations.

Measurement considerations are crucial in the development of substance purchase tasks (for review, see [36]). Critical elements include instructional vignette, selection of optimal unit for purchase, purchase and consumption timeframe, substance specificity (e.g., quality, formulation), environmental variables, and task administration. With respect to the traitlevel MPT specifically, the indicated unit should reflect realworld unit of purchase (i.e., grams). There are differences in unit across MPTs used at present (i.e., joints, hits) which make comparison of findings difficult and potentially impossible. The timeframe over which cannabis will be used is another key MPT component. Qualitative work suggests that timeframe highly impacts demand for cannabis (Aston et al., under review) and should align with typical cannabis 
purchasing behaviors. Constraining the timeframe or permitting ambiguity in the timeframe instructions can engender imprecise results. Moreover, it is important to indicate that cannabis purchased on the MPT must be used within the timeframe and cannot be saved for later use, as the absence of this specification may result in excessive purchasing. The specified amount must be reasonable for consumption within the indicated timeframe. A cap should be included to dissuade biologically implausible amounts which will, in turn, increase extremely outlying values in the data. It is recommended that marijuana quality be similar to what one typically uses. This aligns with purchase tasks for other substances (e.g., alcohol, cigarettes), or if quality is a question of interest, this should be reflected in the instructional set [24]. For cannabis specifically, it is crucial to instruct the participant to indicate the amount of cannabis they would purchase for personal use. This substance is frequently purchased and used with others; thus, it can be complicated to discern the amount consumed for the participant alone. Future research should strive to utilize standardized MPT formats, implementing uniform unit, timeframe, and quality across assessments wherever possible.

While this review represents a comprehensive analysis of MPT studies conducted to date, there are some limitations to note. As MPT research is still in its infancy, the number of studies available for review that met inclusion criteria (i.e., 15) was somewhat low. Moreover, as vignettes differed substantially between studies, we were unable to compare differences in demand indices as a function of instructional set. However, as MPT research continues, additional work may directly assess the way in which small changes in the instructional set impact demand. In addition, several key variables that are likely crucial for cannabis purchase have remained absent from purchase task instructions, including specific strain, THC/CBD concentration, and anticipated effects (e.g., stimulation, sedation). As these criteria are likely to impact demand, their assessment in subsequent research is crucial.

Rigorous assessment of demand for cannabis is an important tool for researchers and policy-makers within the pressing public health issues surrounding cannabis legalization. High-quality cannabis demand assessment has a number of clinical and public health implications, including utility in investigating cannabis cue reactivity to environmental factors (e.g., advertising), individual differences in cannabis' reward valuation and problematic use, and the impact of contextual factors, such as cannabis legalization, on both risky driving and co-use with other substances. The MPT is a valuable behavioral economic instrument and will likely increase our knowledge concerning cannabis abuse liability, taxation policy, and effective treatment for CUD pending its widespread adoption in laboratory and web-based investigations.

Funding Information This study was supported by grants K01DA039311 and T32AA007459.

\section{References}

1. Amlung, M., Marsden, E., Holshausen, K., Morris, V., Patel, H., Vedelago, L., ... McCabe, R. E. (2019). Delay Discounting as a Transdiagnostic Process in Psychiatric Disorders: A Meta-analysis. JAMA Psychiatry. https://doi.org/10.1001/jamapsychiatry.2019. 2102

2. Murphy, J. G., Correia, C. J., \& Barnett, N. P. (2007). Behavioral economic approaches to reduce college student drinking. Addictive Behaviors, 32(11), 2573-2585. https://doi.org/10.1016/j.addbeh. 2007.05.015

3. Zvorsky, I., Nighbor, T. D., Kurti, A. N., DeSarno, M., Naudé, G., Reed, D. D., \& Higgins, S. T. (2019). Sensitivity of hypothetical purchase task indices when studying substance use: A systematic literature review. Preventive Medicine, 105789. https://doi.org/10. 1016/j.ypmed.2019.105789

4. Bickel, W. K., Johnson, M. W., Koffarnus, M. N., MacKillop, J., \& Murphy, J. G. (2014). The behavioral economics of substance use disorders: Reinforcement pathologies and their repair. Annual Review of Clinical Psychology, 10, 641-677. https://doi.org/10. 1146/annurev-clinpsy-032813-153724

5. Roma, P. G., Reed, D. D., DiGennaro Reed, F. D., \& Hursh, S. R. (2017). Progress of and Prospects for Hypothetical Purchase Task Questionnaires in Consumer Behavior Analysis and Public Policy. The Behavior Analyst, 40(2), 329-342. https://doi.org/10.1007/ s40614-017-0100-2

6. Murphy, J. G., \& MacKillop, J. (2006). Relative reinforcing efficacy of alcohol among college student drinkers. Experimental and Clinical Psychopharmacology, 14(2), 219-227. https://doi.org/10. 1037/1064-1297.14.2.219

7. Kaplan, B. A., Foster, R. N. S., Reed, D. D., Arnlung, M., Murphy, J. G., \& MacKillop, J. (2018). Understanding alcohol motivation using the alcohol purchase task: A methodological systematic review. Drug and Alcohol Dependence, 191, 117-140. https://doi. org/10.1016/j.drugalcdep.2018.06.029

8. MacKillop, J. (2016). The Behavioral Economics and Neuroeconomics of Alcohol Use Disorders. Alcoholism: Clinical and Experimental Research, 40(4), 672-685. https://doi.org/10. 1111/acer.13004

9. Tucker, J. A., Cheong, J., Chandler, S. D., Lambert, B. H., Kwok, H., \& Pietrzak, B. (2016). Behavioral economic indicators of drinking problem severity and initial outcomes among problem drinkers attempting natural recovery: A cross-sectional naturalistic study. Addiction (Abingdon, England), 111(11), 1956-1965. https://doi. org/10.1111/add.13492

10. MacKillop, J., \& Murphy, J. G. (2007). A behavioral economic measure of demand for alcohol predicts brief intervention outcomes. Drug and Alcohol Dependence, 89(2-3), 227-233. https:// doi.org/10.1016/j.drugalcdep.2007.01.002

11. MacKillop, J., O’Hagen, S., Lisman, S. A., Murphy, J. G., Ray, L. A., Tidey, J. W., ... Monti, P. M. (2010b). Behavioral economic 
analysis of cue-elicited craving for alcohol. Addiction (Abingdon, England), 105(9), 1599-1607. https://doi.org/10.1111/j.1360-0443. 2010.03004.x

12. MacKillop, J., Amlung, M., Acker, J., \& Stojek, M. (2010a). Further Validation of an Alcohol Purchase Task: Equivalence of Versions for Hypothetical and Actual Rewards. AlcoholismClinical and Experimental Research, 34(6), 48A-48A.

13. Kiselica, A. M., Webber, T. A., Bornovalova, M. A. (2016). Validity of the alcohol purchase task: a meta-analysis. Addiction, 111(5):806-16. https://doi.org/10.1111/add.13254

14. Collins, R. L., Vincent, P. C., Yu, J., Liu, L., \& Epstein, L. H. (2014). A behavioral economic approach to assessing demand for marijuana. Experimental and Clinical Psychopharmacology, 22(3), 211-221. https://doi.org/10.1037/a0035318

15. Aston, E. R., Metrik, J., \& MacKillop, J. (2015). Further validation of a marijuana purchase task. Drug and Alcohol Dependence, 152, 32-38. https://doi.org/10.1016/j.drugalcdep.2015.04.025

16. MacKillop, J., Murphy, J. G., Tidey, J. W., Kahler, C. W., Ray, L. A., \& Bickel, W. K. (2009). Latent structure of facets of alcohol reinforcement from a behavioral economic demand curve. Psychopharmacology, 203(1), 33-40. https://doi.org/10.1007/ s00213-008-1367-5

17. Bidwell, L. C., MacKillop, J., Murphy, J. G., Tidey, J. W., \& Colby, S. M. (2012). Latent factor structure of a behavioral economic cigarette demand curve in adolescent smokers. Addictive Behaviors, 37(11), 1257-1263. https://doi.org/10.1016/j.addbeh.2012.06.009

18. Aston, E. R., Farris, S. G., MacKillop, J., \& Metrik, J. (2017). Latent factor structure of a behavioral economic marijuana demand curve. Psychopharmacology, 234(16), 2421-2429. https://doi.org/ 10.1007/s00213-017-4633-6

19. Metrik, J., Aston, E. R., Kahler, C. W., Rohsenow, D. J., McGeary, J. E., Knopik, V. S., \& MacKillop, J. (2016). Cue-elicited increases in incentive salience for marijuana: Craving, demand, and attentional bias. Drug and Alcohol Dependence. https://doi.org/10.1016/j. drugalcdep.2016.07.027

20. Hindocha, C., Lawn, W., Freeman, T. P., \& Curran, H. V. (2017). Individual and combined effects of cannabis and tobacco on drug reward processing in non-dependent users. Psychopharmacology, 234(21), 3153-3163. https://doi.org/10.1007/s00213-017-4698-2

21. Aston, E. R., Metrik, J., Amlung, M., Kahler, C. W., \& MacKillop, J. (2016). Interrelationships between marijuana demand and discounting of delayed rewards: Convergence in behavioral economic methods. Drug and Alcohol Dependence, 169, 141-147. https://doi.org/10.1016/j.drugalcdep.2016.10.014

22. Strickland, J. C., Lile, J. A., \& Stoops, W. W. (2017). Unique prediction of cannabis use severity and behaviors by delay discounting and behavioral economic demand. Behavioural Processes, 140, 33-40. https://doi.org/10.1016/j.beproc.2017.03.017

23. Strickland, J. C., Lile, J. A., \& Stoops, W. W. (2019a). Contribution of cannabis-related cues to concurrent reinforcer choice in humans. Drug and Alcohol Dependence, 199, 85-91. https://doi.org/10. 1016/j.drugalcdep.2019.02.022

24. Vincent, P. C., Collins, R. L., Liu, L., Yu, J., De Leo, J. A., \& Earleywine, M. (2017). The effects of perceived quality on behavioral economic demand for marijuana: A web-based experiment. Drug and Alcohol Dependence, 170, 174-180.

25. Amlung, M., Reed, D. D., Morris, V., Aston, E. R., Metrik, J., \& MacKillop, J. (2018). Price elasticity of illegal versus legal cannabis: A behavioral economic substitutability analysis. Addiction (Abingdon, England). https://doi.org/10.1111/add.14437
26. Amlung, M., \& MacKillop, J. (2019). Availability of legalized cannabis reduces demand for illegal cannabis among Canadian cannabis users: Evidence from a behavioural economic substitution paradigm. Canadian Journal of Public Health $=$ Revue Canadienne De Sante Publique, 110(2), 216-221. https://doi.org/10.17269/ s41997-018-0160-4

27. Peters, E. N., Rosenberry, Z. R., Schauer, G. L., O'Grady, K. E., \& Johnson, P. S. (2017). Marijuana and tobacco cigarettes: Estimating their behavioral economic relationship using purchasing tasks. Experimental and Clinical Psychopharmacology, 25(3), 208-215. https://doi.org/10.1037/pha0000122

28. Strickland, J. C., Lile, J. A., \& Stoops, W. W. (2019b). Evaluating non-medical prescription opioid demand using commodity purchase tasks: Test-retest reliability and incremental validity. Psychopharmacology, 236(9), 2641-2652. https://doi.org/10. 1007/s00213-019-05234-y

29. Teeters, J., Meshesha, L., Dennhardt, A., \& Murphy, J. (2019). Elevated Demand and Proportionate Substance-related Reinforcement are Associated with Driving after Cannabis Use. The Canadian Journal of Addiction, 10, 42-50. https://doi.org/10. 1097/CXA.0000000000000062

30. Patel, H., \& Amlung, M. (2019). Elevated cannabis demand is associated with driving after cannabis use in a crowd-sourced sample of adults. Experimental and Clinical Psychopharmacology, 27(2), 109-114. https://doi.org/10.1037/pha0000240

31. Gentile, N. D., Librizzi, E. H., \& Martinetti, M. P. (2012). Academic constraints on alcohol consumption in college students: A behavioral economic analysis. Experimental and Clinical Psychopharmacology, 20(5), 390-399. https://doi.org/10.1037/ a0029665

32. Gilbert, L. J., Murphy, J. G., \& Dennhardt, A. A. (2014). A behavioral economic analysis of the effect of next-day responsibilities on drinking. Psychology of Addictive Behaviors: Journal of the Society of Psychologists in Addictive Behaviors, 28(4), 1253-1258. https:// doi.org/10.1037/a0038369

33. Skidmore, J. R., \& Murphy, J. G. (2011). The effect of drink price and next-day responsibilities on college student drinking: A behavioral economic analysis. Psychology of Addictive Behaviors: Journal of the Society of Psychologists in Addictive Behaviors, 25(1), 57-68. https://doi.org/10.1037/a0021118

34. Teeters, J. B., \& Murphy, J. G. (2015). The behavioral economics of driving after drinking among college drinkers. Alcoholism, Clinical and Experimental Research, 39(5), 896-904. https://doi.org/10. 1111/acer.12695

35. Kaplan, B. A., \& Reed, D. D. (2018). Happy hour drink specials in the Alcohol Purchase Task. Experimental and Clinical Psychopharmacology, 26(2), 156-167. https://doi.org/10.1037/ pha0000174

36. Aston, E. R., \& Cassidy, R. N. (2019). Behavioral economic demand assessments in the addictions. Current Opinion in Psychology, 30, 42-47. https://doi.org/10.1016/j.copsyc.2019.01. 016

37. Asbridge, M., Hayden, J. A., \& Cartwright, J. L. (2012). Acute cannabis consumption and motor vehicle collision risk: Systematic review of observational studies and meta-analysis. BMJ (Clinical Research Ed.), 344, e536. https://doi.org/10.1136/ bmj.e536

Publisher's Note Springer Nature remains neutral with regard to jurisdictional claims in published maps and institutional affiliations. 